\title{
Prognostic implications of MRI-detected lateral nodal disease and extramural vascular invasion in rectal cancer
}

Citation for published version (APA):

Schaap, D. P., Ogura, A., Nederend, J., Maas, M., Cnossen, J. S., Creemers, G. J., van Lijnschoten, I., Nieuwenhuijzen, G. A. P., Rutten, H. J. T., \& Kusters, M. (2018). Prognostic implications of MRI-detected lateral nodal disease and extramural vascular invasion in rectal cancer. British Journal of Surgery, 105(13), 1844-1852. https://doi.org/10.1002/bjs.10949

Document status and date:

Published: 01/12/2018

DOI:

10.1002/bjs.10949

Document Version:

Publisher's PDF, also known as Version of record

\section{Document license:}

Taverne

Please check the document version of this publication:

- A submitted manuscript is the version of the article upon submission and before peer-review. There can be important differences between the submitted version and the official published version of record.

People interested in the research are advised to contact the author for the final version of the publication, or visit the DOI to the publisher's website.

- The final author version and the galley proof are versions of the publication after peer review.

- The final published version features the final layout of the paper including the volume, issue and page numbers.

Link to publication

\footnotetext{
General rights rights.

- You may freely distribute the URL identifying the publication in the public portal. please follow below link for the End User Agreement:

www.umlib.nl/taverne-license

Take down policy

If you believe that this document breaches copyright please contact us at:

repository@maastrichtuniversity.nl

providing details and we will investigate your claim.
}

Copyright and moral rights for the publications made accessible in the public portal are retained by the authors and/or other copyright owners and it is a condition of accessing publications that users recognise and abide by the legal requirements associated with these

- Users may download and print one copy of any publication from the public portal for the purpose of private study or research.

- You may not further distribute the material or use it for any profit-making activity or commercial gain

If the publication is distributed under the terms of Article $25 \mathrm{fa}$ of the Dutch Copyright Act, indicated by the "Taverne" license above, 


\title{
Prognostic implications of MRI-detected lateral nodal disease and extramural vascular invasion in rectal cancer
}

\author{
D. P. Schaap ${ }^{1}$ (D) A. Ogura ${ }^{6,9}$, J. Nederend ${ }^{2}$, M. Maas ${ }^{7}$, J. S. Cnossen ${ }^{3}$, G. J. Creemers ${ }^{4}$, \\ I. van Lijnschoten ${ }^{5}$, G. A. P. Nieuwenhuijzen ${ }^{1}$, H. J. T. Rutten ${ }^{1,8}$ and M. Kusters ${ }^{1,6}$ \\ ${ }^{1}$ Departments of Surgery, ${ }^{2}$ Radiology, ${ }^{3}$ Radiation Oncology and ${ }^{4}$ Medical Oncology, Catharina Hospital Eindhoven, and ${ }^{5}$ Pathology Department, \\ Laboratory for Pathology and Medical Microbiology (PAMM), Eindhoven, ${ }^{6}$ Department of Surgery, Leiden University Medical Centre, Leiden, \\ ${ }^{7}$ Department of Radiology, Netherlands Cancer Institute, Amsterdam, and ${ }^{8}$ School for Oncology and Developmental Biology (GROW), Maastricht \\ University, Maastricht, the Netherlands, and ${ }^{9}$ Department of Surgery, Division of Surgical Oncology, Nagoya University Graduate School of Medicine, \\ Nagoya, Japan \\ Correspondence to: Dr M. Kusters, Department of Surgery, Catharina Hospital Eindhoven, Michelangelolaan 2, 5602 ZA, PO Box 1350, Eindhoven, The \\ Netherlands (e-mail: miranda.kusters@cze.nl)
}

\begin{abstract}
Background: Lateral nodal disease in rectal cancer remains a subject of debate and is treated differently in the East and the West. The predictive value of lateral lymph node and MRI-detected extramural vascular invasion (mrEMVI) features on oncological outcomes was assessed in this study.

Methods: In this retrospective cohort study, data on patients with cT3-4 rectal cancer within $8 \mathrm{~cm}$ from the anal verge were considered over a 5-year period (2009-2013). Lateral lymph node size, malignant features and mrEMVI features were evaluated and related to oncological outcomes.

Results: In total, 192 patients were studied, of whom 30 (15.6 per cent) underwent short-course radiotherapy and 145 (75.5 per cent) received chemoradiotherapy. A lateral lymph node short-axis size of $10 \mathrm{~mm}$ or more was associated with a significantly higher 5-year lateral/presacral local recurrence rate of 37 per cent, compared with 7.7 per cent in nodes smaller than $10 \mathrm{~mm}(P=0.041)$. Enlarged nodes did not result in a higher 5 -year rate of distant metastasis ( 23 per cent versus 27.7 per cent in nodes smaller than $10 \mathrm{~mm} ; P=0.563$ ). However, mrEMVI positivity was related to more metastatic disease (5-year rate 43 versus 26.3 per cent in the mrEMVI-negative group; $P=0.014)$, but not with increased lateral/presacral recurrence. mrEMVI occurred in 46.6 per cent of patients with nodes smaller than $10 \mathrm{~mm}$, compared with 29 per cent in patients with nodes of $10 \mathrm{~mm}$ or larger $(P=0.267)$.

Conclusion: Although lateral nodal disease is more a local problem, mrEMVI mainly predicts distant recurrence. The results of this study showed an unacceptably high local recurrence rate in patients with a short axis of $10 \mathrm{~mm}$ or more, despite neoadjuvant (chemo)radiotherapy.
\end{abstract}

Paper accepted 18 June 2018

Published online 6 August 2018 in Wiley Online Library (www.bjs.co.uk). DOI: 10.1002/bjs.10949

\section{Introduction}

Despite the accuracy of preoperative planning with MRI and standardized surgical techniques for patients with rectal cancer, the local recurrence rate remains between 5 and 10 per cent, and it is difficult to lower this further ${ }^{1}$. It is hypothesized, especially in the East, that malignant lateral lymph nodes located around the iliac vessels and the obturator compartment could be the underlying cause of local recurrence after $\mathrm{R} 0$ resection, especially in distal cT3 -4 cancers, which are more at risk of lateral spread ${ }^{2}$. However, there remains a lack of international consensus about the treatment of these nodes. In the West, lateral nodal disease is not considered for routine surgical treatment and is thought to be eradicated with neoadjuvant (chemo)radiotherapy, whereas a lateral lymph node dissection (LLND) is preferred in the East ${ }^{3}$. Another belief of Western surgeons is that lateral nodal disease is a sign of metastatic disease, not amenable to cure.

Several Korean centres (that do not perform LLND) have shown increased local recurrence rates in patients with enlarged lateral lymph nodes on preoperative staging treated with neoadjuvant (chemo)radiotherapy and TME, suggesting this may be insufficient for adequate disease control $^{4-6}$. A recent small UK series ${ }^{7}$ suggested similar trends, with a high lateral local recurrence rate in patients with a lymph node short axis larger than $10 \mathrm{~mm}$. In 
enlarged nodes, the combination of neoadjuvant chemoradiotherapy (CRT) and LLND in a Japanese series ${ }^{8}$ resulted in low local recurrence rates and good disease-free survival, suggesting that lateral nodal disease is a local problem that can be cured. However, despite neoadjuvant therapy and surgery with clear margins, the presacral region is a common site for the development of local recurrence ${ }^{9-12}$. As the presacral plane is one of the easiest to dissect during surgery, the aetiology is curious. It has been hypothesized that the drainage of residual tumour cells from the lateral lymph node basins might be one reason ${ }^{13}$.

Extramural vascular invasion (EMVI) is also associated with recurrent and metastatic disease ${ }^{14-17}$. Recently, six studies on the predictive value of MRI-detected EMVI (mrEMVI) for the development of distant metastasis were combined in a meta-analysis $(1262 \text { patients })^{18}$. One-third of the patients had mrEMVI, which was associated with a quadrupled rate of metachronous metastases compared with that in patients without mrEMVI. Gaining additional insight into the unfavourable factors for the development of local recurrence and metastatic disease aids treatment planning and the development of personalized strategies. This study examined the role of lateral nodal disease, mrEMVI and the effect of neoadjuvant therapy on the development of local recurrence and metastasis in patients with low cT3-4 rectal cancer.

\section{Methods}

All patients who had undergone surgery for cT3 or cT4 rectal cancer between January 2009 and December 2013 at Catharina Hospital, Eindhoven, a tertiary referral hospital for locally advanced and recurrent rectal cancer in the Netherlands, were identified from a database. Patients with a tumour within $8 \mathrm{~cm}$ from the anal verge (measured on sagittal MRI) were included. All MRI scans were rereviewed, and data regarding treatment and oncological follow-up were obtained. Reasons for exclusion were poor quality or lack of MRI images or metastatic disease at the time of presentation.

\section{Radiological assessment}

For all included patients, MRI scans taken at diagnosis and after neoadjuvant treatment were re-evaluated. T2-weighted images were obtained in the sagittal and transversal planes. Slice thickness varied between 3 and $5 \mathrm{~mm}$; different machines were used for imaging because the patients were referred from different hospitals. First, an experienced abdominal radiologist evaluated all MRI scans to determine the height and length of the tumour as well as

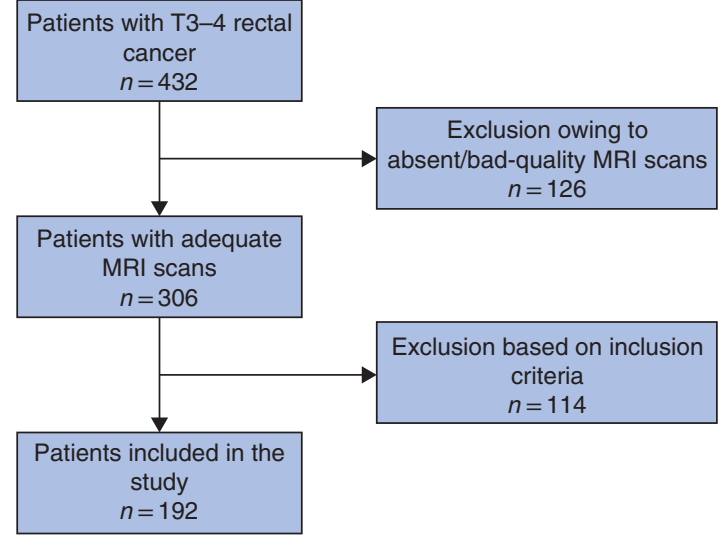

Fig. 1 Flow diagram summarizing inclusion and exclusion criteria

the cTNM stage and involvement of the mesorectal fascia (MRF). The height of the tumour was assessed according to both the criterion of the low rectal cancer national development programme (LOREC) and the Japanese definition of low rectal cancer ${ }^{19}$. The LOREC criterion defines low rectal cancer as a tumour of which the distal part is located below the attachment of the levator muscles to the pelvic bone, measured on axial T2 images. According to the Japanese definition, tumours of which the major part is situated at or below the peritoneal reflection are called low rectal cancers.

In addition to standard staging, the lateral lymph node status was evaluated. The largest lateral lymph node on pretreatment MRI was used and assessed for both longand short-axis length, side and site (internal iliac, external iliac or obturator compartment). The presence of malignant features, such as internal heterogeneity or border irregularity, were noted for enlarged lateral lymph nodes. Potential changes in the size and presence of malignant features of this same lateral node after neoadjuvant treatment were also evaluated for patients where a restaging MRI was available. The benign long-stretched nodes, located just behind the distal portion of the external iliac vein, were not included in the assessment.

In addition, all the MRI scans were re-evaluated by a second mrEMVI-trained radiologist for the presence of mrEMVI, the size of the deposit, extent of invasion and the location of the vein involved (inferior, medial and superior rectal).

\section{Treatment strategies}

All patients were discussed in a multidisciplinary team meeting. Neoadjuvant treatment consisted of either $5 \times 5$-Gy short-course radiotherapy for patients with a 
Table 1 Baseline characteristics

\begin{tabular}{|c|c|}
\hline & $\begin{array}{l}\text { No. of patients } \\
\quad(n=192)\end{array}$ \\
\hline Age $($ years $) \dagger$ & $67(28-85)$ \\
\hline Sex ratio $(M: F)$ & $122: 70$ \\
\hline \multicolumn{2}{|l|}{ cT category based on MRI } \\
\hline cT3 & $105(54 \cdot 7)$ \\
\hline cT4 & $87(45 \cdot 3)$ \\
\hline \multicolumn{2}{|l|}{$\mathrm{cN}$ category based on MRI } \\
\hline cNO & $66(34.4)$ \\
\hline $\mathrm{cN} 1$ & $50(26 \cdot 0)$ \\
\hline $\mathrm{cN} 2$ & $76(39.6)$ \\
\hline \multicolumn{2}{|l|}{ Compartment of largest lateral node $(n=116) \ddagger$} \\
\hline Internal iliac & $24(20 \cdot 7)$ \\
\hline External iliac & $6(5 \cdot 2)$ \\
\hline Obturator & $86(74 \cdot 1)$ \\
\hline \multicolumn{2}{|l|}{ Malignant features $(n=116) \ddagger$} \\
\hline None§ & $68(58.6)$ \\
\hline Internal heterogeneity & $16(13 \cdot 8)$ \\
\hline Border irregularity & $9(7 \cdot 8)$ \\
\hline Internal heterogeneity and border irregularity & $23(19.8)$ \\
\hline \multicolumn{2}{|l|}{ Type of neoadjuvant treatment } \\
\hline None & $17(8.9)$ \\
\hline $5 \times 5$ Gy & $30(15 \cdot 6)$ \\
\hline Chemoradiotherapy & $145(75.5)$ \\
\hline \multicolumn{2}{|l|}{ Type of surgery } \\
\hline LAR/Hartmann procedure & $91(47.4)$ \\
\hline APR & $55(28.6)$ \\
\hline Extended resection & $46(24.0)$ \\
\hline \multicolumn{2}{|l|}{ Application of IORT } \\
\hline No & $145(75.5)$ \\
\hline Yes & $47(24.5)$ \\
\hline
\end{tabular}

*With percentages in parentheses unless indicated otherwise; †values are median (range). \$Only 116 patients had visible lymph nodes; §lymph node visible, but no malignant features. LAR, low anterior resection; APR, abdominoperineal resection; IORT, intraoperative radiotherapy.

cT3 tumour without an involved MRF or long-course CRT consisting of 45-50 Gy in fractions of 1.8-2 Gy with concomitant oral chemotherapy. For medical reasons, two patients received only long-course radiotherapy without additional chemotherapy. For all rectal tumours with the distal border situated within $8 \mathrm{~cm}$ from the anal verge, the obturator and internal and external iliac compartments were located in the standard irradiation field.

All patients underwent (extended) surgery with curative intent. There was no consensus on the surgical treatment of lateral nodal disease. Additional intraoperative radiotherapy (IORT) was applied if there was an area at risk of a threatened margin. No patient received adjuvant CRT.

\section{Local recurrence}

All the patients were monitored for at least 5 years according to the standard follow-up programme consisting of
Table 2 MRI variables versus short-axis lymph node size

\begin{tabular}{|c|c|c|c|}
\hline & $\begin{array}{c}\text { Short-axis } \\
\text { size }<10 \mathrm{~mm} \\
\quad(n=178)\end{array}$ & $\begin{array}{c}\text { Short-axis } \\
\text { size } \geq 10 \mathrm{~mm} \\
(n=14)\end{array}$ & $P^{*}$ \\
\hline mrEMVI & & & 0.267 \\
\hline No & $95(53.4)$ & $10(71)$ & \\
\hline Yes & $83(46 \cdot 6)$ & $4(29)$ & \\
\hline LOREC criterion & & & 0.637 \\
\hline No & $56(31.5)$ & $3(21)$ & \\
\hline Yes & $122(68.5)$ & $11(79)$ & \\
\hline Below peritoneal reflection & & & 1.000 \\
\hline No & $20(11 \cdot 2)$ & $1(7)$ & \\
\hline Yes & $158(88 \cdot 8)$ & $13(93)$ & \\
\hline Long-axis size (mm) & & & $<0.001$ \\
\hline No visible nodes & $76(42 \cdot 7)$ & $0(0)$ & \\
\hline $1-5$ & $29(16 \cdot 3)$ & $0(0)$ & \\
\hline $6-10$ & $58(32 \cdot 6)$ & $0(0)$ & \\
\hline $11-15$ & $14(7 \cdot 9)$ & $1(7)$ & \\
\hline$>15$ & $1(0 \cdot 6)$ & $13(93)$ & \\
\hline Site & & & $<0.001$ \\
\hline No visible nodes & $76(42 \cdot 7)$ & $0(0)$ & \\
\hline External iliac & $6(3.4)$ & $0(0)$ & \\
\hline Internal iliac & $17(9 \cdot 6)$ & $7(50)$ & \\
\hline Obturator & $79(44.4)$ & $7(50)$ & \\
\hline Malignant features & & & $<0.001$ \\
\hline No visible nodes & $76(42 \cdot 7)$ & $0(0)$ & \\
\hline No malignant features & $68(38 \cdot 2)$ & $0(0)$ & \\
\hline Malignant features & $34(19 \cdot 1)$ & $14(100)$ & \\
\hline
\end{tabular}

Values in parentheses are percentages. mrEMVI, MRI-detected extramural vascular invasion; LOREC, low rectal cancer national development programme. ${ }^{*} \chi^{2}$ test.

routine measurement of the carcinoembryonic antigen level and CT, and, if indicated, MRI or PET. When there was local recurrence, the MRI scan was rereviewed. Local recurrence was classified by the following, previously described $^{11}$, locations: anterior, lateral, presacral, perineal or anastomotic site.

\section{Statistical analysis}

Statistical analyses were performed using the IBM SPSS ${ }^{\circledR}$ statistical package version 23 (IBM, Armonk, New York, USA). $P<0.050$ was considered significant. Individual variables were compared with $t$ tests and the $\chi^{2}$ test. Local recurrence, distant metastasis, and cancer-free and overall survival curves were constructed using the Kaplan-Meier method and compared with the log rank test. To determine the risk factors, the effects of co-variables were analysed using a univariable Cox regression model. Subsequently, multivariable analysis was performed for co-variables that showed a significant effect in the univariable analysis $(P<0 \cdot 100)$. In this study, $\mathrm{cN}$ and (y)pN categories refer to mesorectal node stage. 
Table 3 Pathological outcomes

\begin{tabular}{lc} 
& $\begin{array}{c}\text { No. of patients } \\
(n=192)\end{array}$ \\
& \\
(y)pT category & $27(14 \cdot 1)$ \\
(y)pT0 & $11(5 \cdot 7)$ \\
(y)pT1 & $51(26 \cdot 6)$ \\
(y)pT2 & $81(42 \cdot 2)$ \\
(y)pT3 & $22(11 \cdot 5)$ \\
(y)pT4 & \\
(y)pN category & $129(67 \cdot 2)$ \\
(y)pN0 & $37(19 \cdot 3)$ \\
(y)pN1 & $26(13 \cdot 5)$ \\
(y)pN2 & \\
Margin involvement & $179(93 \cdot 2)$ \\
R0 & $13(6 \cdot 8)$ \\
R1 & $7(3 \cdot 6)$ \\
No. of patients with resected lateral lymph nodes & 11 \\
Total no. of harvested lateral lymph nodes & 5 of $7(71)$ \\
Pathologically confirmed lateral lymph node disease & \\
Venous invasion & $182(94 \cdot 8)$ \\
No & $10(5 \cdot 2)$ \\
Yes & \\
\hline
\end{tabular}

${ }^{*}$ With percentages in parentheses unless indicated otherwise.

\section{Results}

Of a total of 432 patients with cT3-4 rectal tumours treated between 2009 and 2013, 192 with a tumour located within $8 \mathrm{~cm}$ of the anal verge were included (Fig. 1). The mean duration of follow-up after surgery was 51 (range $1-100$ ) months. The median age of patients was 67 (range $28-85$ ) years, and 63.5 per cent were men. Further baseline characteristics are shown in Table 1.

\section{Baseline MRI staging}

At baseline, 116 patients (60.4 per cent) had at least one visible lateral lymph node, of which 48 ( 41.4 per cent) had one or more malignant features. Table 2 shows MRI variables that were related to the short-axis size. mrEMVI was present at baseline in 87 patients $(45.3$ per cent). No association was found between the occurrence of lateral lymph node enlargement and EMVI; of the 87 patients with mrEMVI positivity, 53 (61 per cent) had enlarged lateral nodes, compared with 63 of 105 patients $(60.0$ per cent $)$ in the mrEMVI-negative group $(P=0 \cdot 897)$. Thirteen of the 14 patients who had short-axis nodes of $10 \mathrm{~mm}$ or more received neoadjuvant CRT, and one received a dose of $5 \times 5$ Gy.

\section{Restaging MRI}

Restaging MRI after (chemo)radiotherapy was performed in 154 patients $(80 \cdot 2$ per cent). Neoadjuvant therapy had a

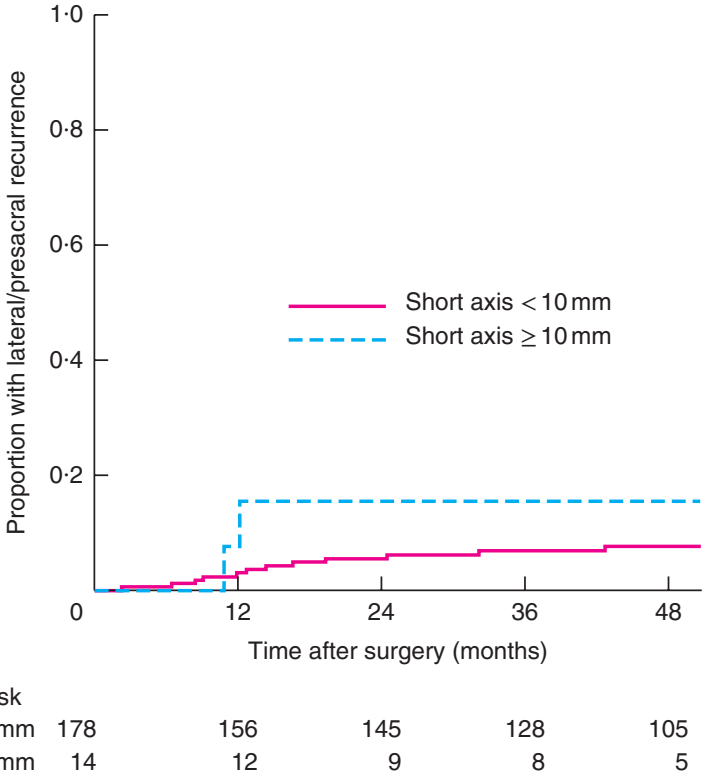

Fig. 2 Kaplan-Meier analysis of lateral and presacral local recurrence according to short-axis lymph node size. $P=0 \cdot 041$ (log rank test)

downsizing effect on the lateral lymph node in $100(86 \cdot 2$ per cent) of 116 patients with enlarged lateral nodes, of whom 31 (26.7 per cent) had no visible nodes left after neoadjuvant therapy. Short-axis growth of the nodes was visible in nine patients ( 7.8 per cent), and in six (5.2 per cent) the nodes remained stable.

\section{Surgery and pathology findings}

The majority of the patients underwent a low anterior or Hartmann's resection (91 patients, 47.4 per cent), 55 (28.6 per cent) had an abdominoperineal resection, and in 46 (24.0 per cent) extended surgery was performed, in which (partial) adjacent organs were resected (Table 1). In 179 patients (93.2 per cent), an R0 resection was achieved. IORT was used in 47 patients ( 24.5 per cent). Additionally, clinically suspected lateral lymph nodes were harvested selectively in seven patients, of whom five had a pathologically confirmed positive lateral lymph node status. The mean pretreatment short-axis size of these nodes was 14 (range 4-19) $\mathrm{mm}$. Of the 87 patients with mrEMVI, pathological venous invasion was present in seven $(8 \cdot 0$ per cent). Pathological outcomes are outlined in Table 3.

\section{Local recurrence and lateral lymph node features}

Twenty-three of the 192 patients developed local recurrence, resulting in a 5-year local recurrence rate of $13 \cdot 3$ 
Table 4 Univariable analysis of oncological outcomes

\begin{tabular}{|c|c|c|c|c|c|c|}
\hline & \multicolumn{2}{|c|}{ Lateral/presacral local recurrence } & \multicolumn{2}{|c|}{ Local recurrence } & \multicolumn{2}{|c|}{ Distant metastasis } \\
\hline & Hazard ratio & $P$ & Hazard ratio & $P$ & Hazard ratio & $P$ \\
\hline Age (years) & & 0.222 & & 0.158 & & 0.864 \\
\hline$\leq 67$ & 1.00 (reference) & & 1.00 (reference) & & 1.00 (reference) & \\
\hline$\geq 68$ & $0.52(0.18,1.49)$ & & $2.86(0.66,12.30)$ & & $1.04(0.64,1.71)$ & \\
\hline Sex & & 0.650 & & 0.802 & & 0.258 \\
\hline $\mathrm{F}$ & 1.00 (reference) & & 1.00 (reference) & & 1.00 (reference) & \\
\hline$M$ & $1.28(0.44,3.68)$ & & $0.90(0.39,2.08)$ & & $1.36(0.80,2.34)$ & \\
\hline cT category & & 0.378 & & 0.497 & & 0.677 \\
\hline cT3 & 1.00 (reference) & & 1.00 (reference) & & 1.00 (reference) & \\
\hline cT4 & $1.56(0.58,4.19)$ & & $1.33(0.59,3.01)$ & & $0.90(0.55,1.48)$ & \\
\hline cN category & & 0.493 & & 0.505 & & 0.136 \\
\hline cNO & 1.00 (reference) & & 1.00 (reference) & & 1.00 (reference) & \\
\hline $\mathrm{cN} 1$ & $2.13(0.60,7.55)$ & & $1.88(0.65,5.42)$ & & $1.44(0.73,2.85)$ & \\
\hline $\mathrm{cN} 2$ & $1.41(0.40,5.01)$ & & $1.41(0.50,3.96)$ & & $1.85(1.01,3.40)$ & \\
\hline Short-axis on MRI (mm) & & 0.055 & & 0.250 & & 0.500 \\
\hline$<10$ & 1.00 (reference) & & 1.00 (reference) & & 1.00 (reference) & \\
\hline$\geq 10$ & $3.44(0.98,12.12)$ & & $2.04(0.61,6.89)$ & & $0.67(0.21,2.14)$ & \\
\hline Long-axis on MRI (mm) & & 0.071 & & 0.079 & & 0.561 \\
\hline No visible nodes & 1.00 (reference) & & 1.00 (reference) & & 1.00 (reference) & \\
\hline $1-5$ & $1.81(0.41,8.09)$ & & $0.80(0.22,2.97)$ & & $0.65(0.30,1.41)$ & \\
\hline $6-10$ & $1.28(0.32,5 \cdot 13)$ & & $0.71(0.24,2.11)$ & & $0.90(0.51,1.59)$ & \\
\hline $11-15$ & $1.42(0.16,12 \cdot 70)$ & & $1.27(0.27,5.87)$ & & $0.35(0.08,1.47)$ & \\
\hline$>15$ & $6 \cdot 76(1.67,27 \cdot 36)$ & & $3.00(0.92,9.81)$ & & $0.80(0.28,2.29)$ & \\
\hline Malignant features & & 0.451 & & 0.771 & & 0.438 \\
\hline No & 1.00 (reference) & & 1.00 (reference) & & 1.00 (reference) & \\
\hline Yes & $1.55(0.45,4.79)$ & & $1.17(0.41,3.38)$ & & $1.31(0.66,2.57)$ & \\
\hline mrEMVI & & 0.323 & & 0.046 & & 0.022 \\
\hline No & 1.00 (reference) & & 1.00 (reference) & & 1.00 (reference) & \\
\hline Yes & $1.65(0.61,4.42)$ & & $2.39(1.01,5.65)$ & & $1.79(1.09,2.95)$ & \\
\hline Neoadjuvant treatment & & 0.780 & & 0.684 & & 0.551 \\
\hline None & 1.00 (reference) & & 1.00 (reference) & & 1.00 (reference) & \\
\hline $5 \times 5 \mathrm{~Gy}$ & $0.51(0.07,3.65)$ & & $0.53(0.11,2.61)$ & & $1.39(0.49,3.96)$ & \\
\hline CRT & $0.63(0.14,2.81)$ & & $0.61(0.18,2.08)$ & & $0.98(0.39,2.47)$ & \\
\hline Type of surgery & & 0.253 & & 0.483 & & 0.182 \\
\hline LAR & 1.00 (reference) & & 1.00 (reference) & & 1.00 (reference) & \\
\hline APR & $2.64(0.85,8.32)$ & & $1.45(0.54,3.90)$ & & $0.98(0.52,1.82)$ & \\
\hline Extended resection & $1.88(0.50,7.02)$ & & $1.82(0.68,4.89)$ & & $1.65(0.92,2.94)$ & \\
\hline Margin involvement & & 0.001 & & $<0.001$ & & 0.006 \\
\hline RO & 1.00 (reference) & & 1.00 (reference) & & 1.00 (reference) & \\
\hline $\mathrm{R} 1$ & $7 \cdot 10(2 \cdot 22,22 \cdot 65)$ & & $5.65(2.06,15.48)$ & & $3.04(1.37,6.74)$ & \\
\hline
\end{tabular}

Values in parentheses are 95 per cent confidence intervals. mrEMVI, MRI-detected extramural vascular invasion; CRT, chemoradiotherapy; LAR, low anterior resection; APR, abdominoperineal resection.

per cent. Eleven of these local recurrences occurred in the lateral compartment, five in the presacral region, two in the perineal compartment and five at the anastomosis site. The 5 -year lateral local recurrence rate was $5 \cdot 2$ per cent; when presacral local recurrence was included, this resulted in a lateral/presacral local recurrence rate of 7.8 per cent. Lateral/presacral local recurrence rates, according to the short-axis lateral lymph node size, are shown in Fig. 2. Lymph node size with a short axis of $10 \mathrm{~mm}$ or more was associated with a high 5 -year lateral/presacral local recurrence rate of 37 per cent, compared with a rate of 7.7 per cent for nodes smaller than $10 \mathrm{~mm}(P=0 \cdot 041)$. When only the lateral local recurrence rate was considered, the difference was not significant ( 31 versus 5 per cent respectively; $P=0.088)$. There was no difference in lateral/presacral or general local recurrence rates according to the compartment of the affected node. Furthermore, the seven patients in whom a selective lateral lymph node resection was performed had a 5 -year lateral/presacral local recurrence rate of 67 per cent.

The 5-year lateral/presacral local recurrence rate in the 100 patients who achieved complete remission or a reduction in the size of the lateral lymph nodes on MRI after neoadjuvant treatment was $10 \cdot 8$ per cent, compared with 46 
Table 5 Univariable analysis of survival

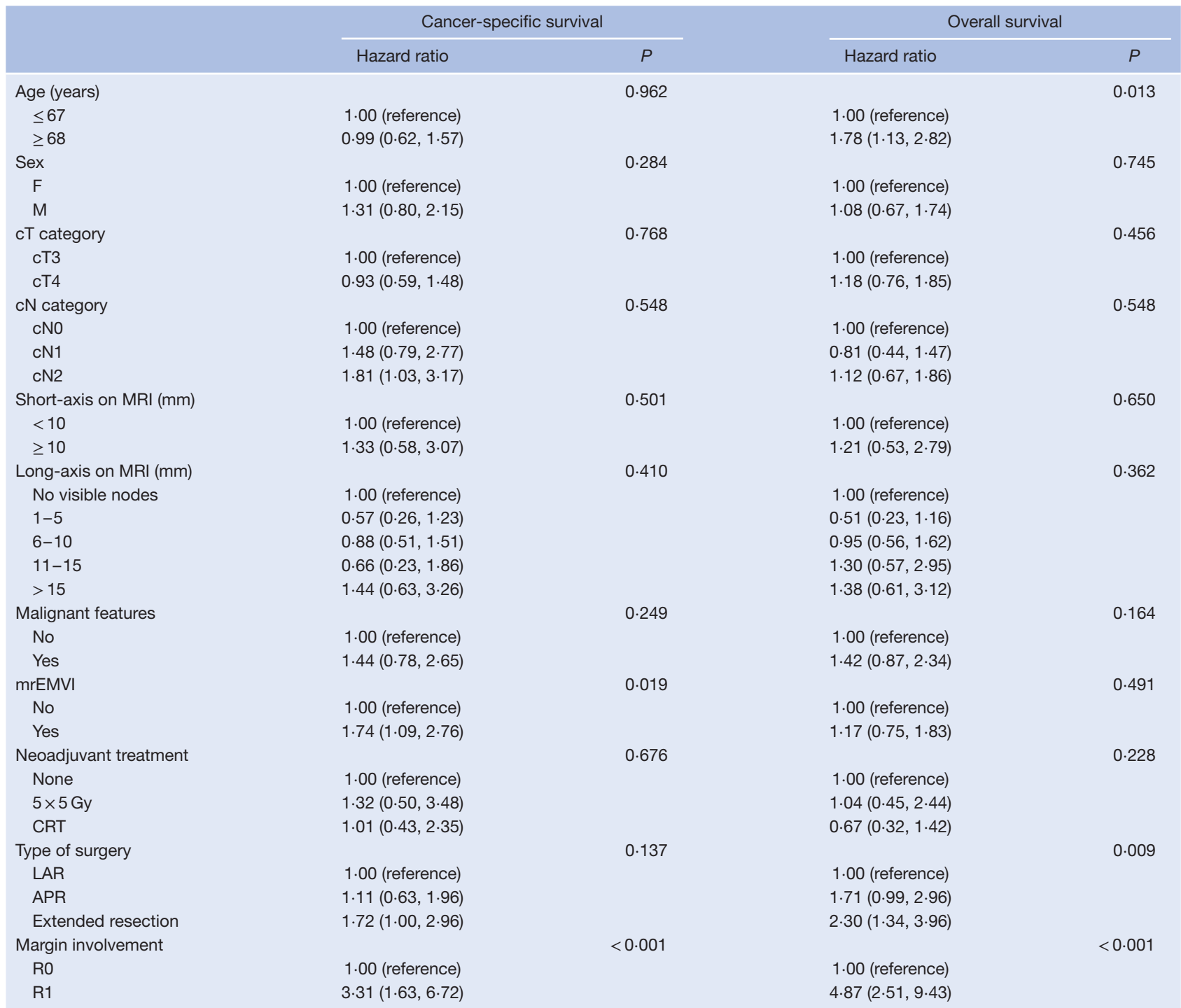

Values in parentheses are 95 per cent confidence intervals. mrEMVI, MRI-detected extramural vascular invasion; CRT, chemoradiotherapy; LAR, low anterior resection; APR, abdominoperineal resection.

per cent in patients with stable lateral lymph nodes. However, the number of events was too low to perform a reliable statistical analysis.

Univariable and multivariable analyses are shown in Tables 4-6. CRM involvement was the main predictor of local recurrence. In both univariable and multivariable analyses, lateral lymph nodes with a short axis of $10 \mathrm{~mm}$ or more were associated with increased lateral/presacral local recurrence rates. The likelihood of developing lat$\mathrm{eral} / \mathrm{presacral}$ local recurrence was almost fivefold higher in patients with nodes of $10 \mathrm{~mm}$ or above (hazard ratio 4.83 , 95 per cent c.i. 1.30 to 17.98 ) (Table 6).

\section{Local recurrence and MRI-detected extramural vascular invasion}

mrEMVI did not influence the 5-year lateral/presacral local recurrence rate $(13$ per cent versus 6.5 per cent in the mrEMVI-negative group; $P=0.318$ ) but did influence general local recurrence, leading to a 5 -year local recurrence rate of 20 versus 7.6 per cent respectively $(P=0.040)$. The occurrence of tumour deposits in 87 mrEMVI-positive patients had no significant effect on the 5 -year overall local recurrence rate: 22 per cent in the 45 patients with deposits versus 21 per cent in the 42 patients 
Table 6 Multivariable analysis

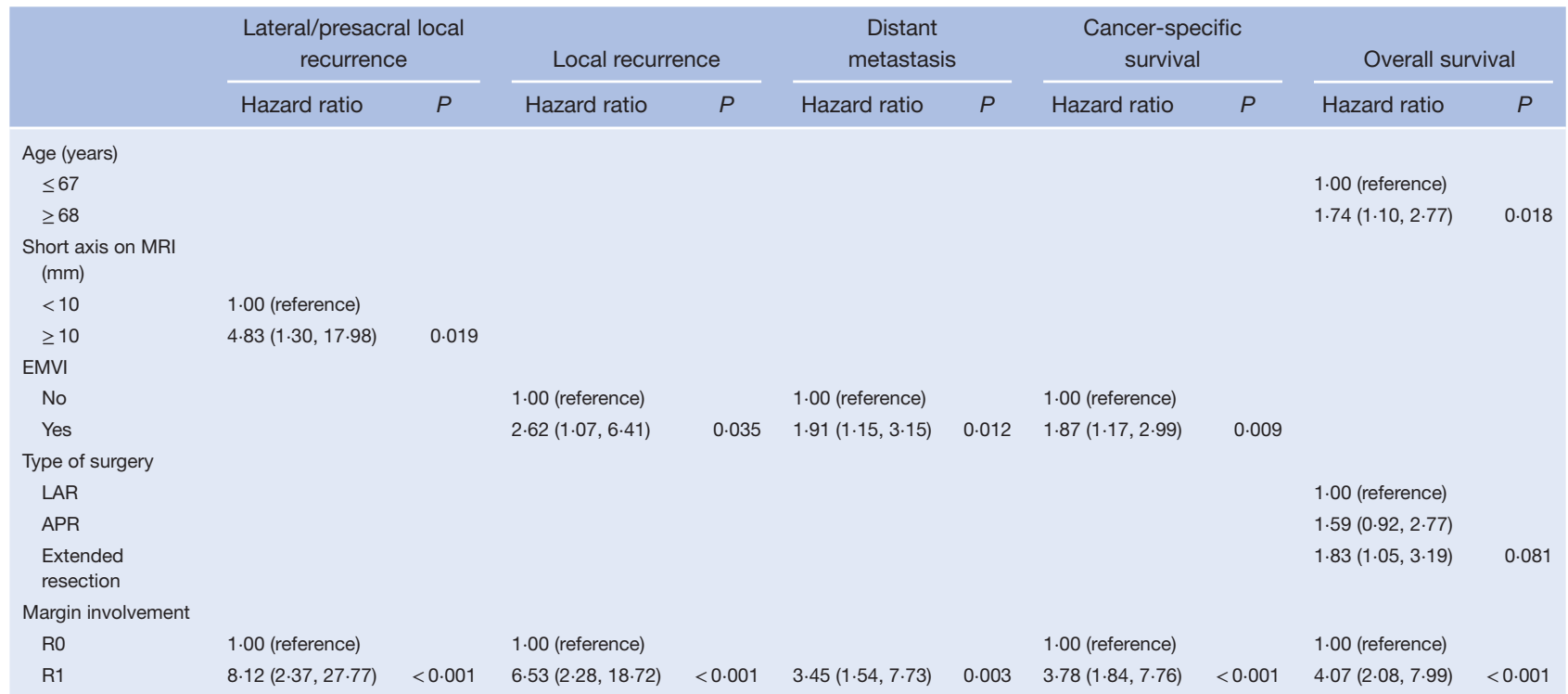

Values in parentheses are 95 per cent confidence intervals. Because the short and long axis are related to one another, only the short axis was included in the multivariable analysis. EMVI, extramural vascular invasion; LAR, low anterior resection; APR, abdominoperineal resection.

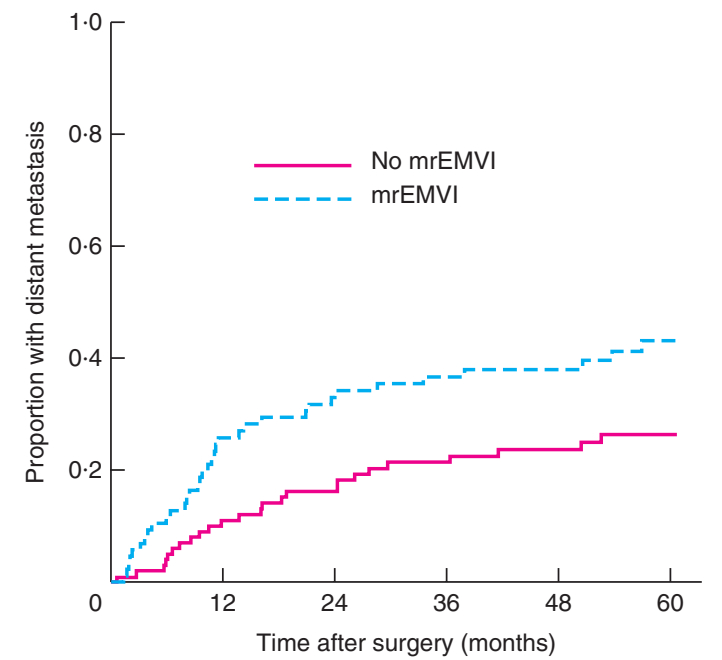

No. at risk $\begin{array}{lrrrrrr}\text { No mrEMVI } & 105 & 87 & 81 & 72 & 60 & 40 \\ \text { mrEMVI } & 87 & 63 & 55 & 51 & 41 & 30\end{array}$

Fig. 3 Kaplan-Meier analysis of distant metastasis according to presence or absence of MRI-detected extramural vascular invasion (mrEMVI). $P=0 \cdot 014$ (log rank test)

without deposits $(P=0 \cdot 774)$. Furthermore, if considering only lateral and presacral recurrence, the 5 -year recurrence rate was 11 and 16 per cent respectively $(P=0 \cdot 307)$.

\section{Distant metastases and survival}

At 5 years, 44.0 per cent of the patients had developed distant metastases. CRM involvement was a strong predictor of increased distant metastasis and decreased cancer-specific and overall survival rates. Lateral nodal enlargement neither resulted in a higher 5-year metastatic disease rate $(23$ per cent versus 27.7 per cent in nodes smaller than $10 \mathrm{~mm} ; P=0.563$ ) nor influenced (disease-free) survival. In addition to CRM involvement, mrEMVI was also associated with a higher risk of developing distant metastasis, with a rate of 43 per cent, compared with 26.3 per cent in patients without mrEMVI involvement $(P=0.014)$ (Fig. 3). In addition, mrEMVI was related to a lower cancer-specific survival rate $(P=0 \cdot 009)$. The presence of tumour deposits in mrEMVI-positive patients did not influence the 5-year metastasis rate, and the location of venous invasion did not show any relation with distant metastasis.

\section{Treatment of lateral/presacral local recurrence}

Metastatic disease was observed in six of 16 patients with lateral or presacral local recurrence at the time of diagnosis. These 16 patients had a mean overall survival of 21 (median 13, range 2-62) months. Ten patients were considered to have curable disease and commenced neoadjuvant (chemo)reirradiation; seven eventually underwent surgery and the others received palliative treatment owing 
to the occurrence or progression of metastatic disease during neoadjuvant treatment. One patient died from another cause. Three of the seven patients who had surgery underwent resection of the recurrence with involved margins; their mean overall survival of 21 (median 23, range 2-37) months was almost threefold lower than that of the four patients who had an R0 resection: mean 59 (median 55, range 28-97) months.

\section{Discussion}

This study found that a lateral lymph node short-axis size of $10 \mathrm{~mm}$ or more was a major risk factor for local recurrence but not for distant metastasis or survival. mrEMVI was an important predictor of the development of distant metastasis and diminished cancer-free survival. These results support the idea that lateral lymph node disease and EMVI are two different tumour factors, independent of one another despite the common origin.

Dealing with a local recurrence is a major challenge, associated with significant morbidity, but even after reresection patients have a mean survival of 3 years. Specifically, local recurrences located in dorsal and lateral subsites are associated with fewer R0 resections and diminished survival rates $^{20}$. It would be ideal to reduce the development of local recurrence by treating primary lateral nodal disease more intensively. A small proportion of patients with low cT3-4 rectal cancers have nodes of $10 \mathrm{~mm}$ or greater, so conducting trials represents a challenge.

A more intensified radiotherapeutic regimen in addition to (or instead of) induction treatment might be one option. It is known from gynaecological tumours that up to $60 \mathrm{~Gy}$ can be applied to the lateral side-wall nodes without significantly increasing morbidity ${ }^{21}$. Whether restaging MRI assessment of lateral nodal disease is sensitive enough to confirm lateral nodal response is not known, because the numbers were too low to define the role of restaging MRI in the present study. In selected patients, formal LLND of the whole internal iliac and obturator compartments might be necessary.

A weakness of this study is the low patient numbers; low cT3-4 cancers are relatively uncommon and only a minor proportion of these patients develop local recurrence. The limitations of a retrospective, single-centre study are apparent, so the statistical analyses should be interpreted with caution. Although many questions remain, this study found lateral nodal disease to be a major local problem despite neoadjuvant treatment. Lateral nodal disease was not associated with systemic disease, indicating that it may be cured if recognized and treated adequately. The presence of mrEMVI may also necessitate a change in preoperative treatment, such as the use of induction chemotherapy.

A large multicentre study should provide a greater body of evidence regarding the prognostic value of lateral lymph node size and features. The role of restaging MRI in the evaluation of EMVI and lateral nodes should also be investigated.

\section{Disclosure}

The authors declare no conflict of interest.

\section{References}

1 Kodeda K, Johansson R, Zar N, Birgisson H, Dahlberg M, Skullman $\mathrm{S}$ et al. Time trends, improvements and national auditing of rectal cancer management over an 18-year period. Colorectal Dis 2015; 17: O168-O179.

2 Hojo K, Koyama Y. Postoperative follow-up studies on cancer of the colon and rectum. Am $\mathcal{F}$ Surg 1982; 143: 293-293.

3 Moriya Y, Sugihara K, Akasu T, Fujita S. Nerve-sparing surgery with lateral node dissection for advanced lower rectal cancer. Eur 7 Cancer 1995; 31: 1229-1232.

4 Kim MJ, Kim TH, Kim DY, Kim SY, Baek JY, Chang HJ et al. Can chemoradiation allow for omission of lateral pelvic node dissection for locally advanced rectal cancer? 7 Surg Oncol 2015; 111: 459-464.

5 Kim TG, Park W, Choi DH, Park HC, Kim SH, Cho YB et al. Factors associated with lateral pelvic recurrence after curative resection following neoadjuvant chemoradiotherapy in rectal cancer patients. Int 7 Colorectal Dis 2014; 29 : 193-200.

6 Kim TH, Jeong SY, Choi DH, Kim DY, Jung KH, Moon $\mathrm{SH}$ et al. Lateral lymph node metastasis is a major cause of locoregional recurrence in rectal cancer treated with preoperative chemoradiotherapy and curative resection. Ann Surg Oncol 2008; 15: 729-737.

7 Kusters M, Slater A, Muirhead R, Hompes R, Guy RJ, Jones $\mathrm{OM}$ et al. What to do with lateral nodal disease in low locally advanced rectal cancer? A call for further reflection and research. Dis Colon Rectum 2017; 60: 577-585.

8 Akiyoshi T, Ueno M, Matsueda K, Konishi T, Fujimoto Y, Nagayama $S$ et al. Selective lateral pelvic lymph node dissection in patients with advanced low rectal cancer treated with preoperative chemoradiotherapy based on pretreatment imaging. Ann Surg Oncol 2014; 21: 189-196.

9 Calvo FA, Gómez-Espí M, Díaz-González JA, Alvarado A, Cantalapiedra R, Marcos P et al. Intraoperative presacral electron boost following preoperative chemoradiation in T3-4 Nx rectal cancer: initial local effects and clinical outcome analysis. Radiother Oncol 2002; 62: 201-206.

10 Kusters M, Holman FA, Martijn H, Nieuwenhuijzen GA, Creemers GJ, Daniels-Gooszen AW et al. Patterns of local recurrence in locally advanced rectal cancer after 
intra-operative radiotherapy containing multimodality treatment. Radiother Oncol 2009; 92: 221-225.

11 Kusters M, Marijnen CA, van de Velde CJ, Rutten HJ, Lahaye MJ, Kim JH et al. Patterns of local recurrence in rectal cancer; a study of the Dutch TME trial. Eur 7 Surg Oncol 2010; 36: 470-476.

12 Roeder F, Treiber M, Oertel S, Dinkel J, Timke C, Funk A et al. Patterns of failure and local control after intraoperative electron boost radiotherapy to the presacral space in combination with total mesorectal excision in patients with locally advanced rectal cancer. Int 7 Radiat Oncol Biol Phys 2007; 67: 1381-1388.

13 Kusters M, Wallner C, Lange MM, DeRuiter MC, van de Velde CJ, Moriya Y et al. Origin of presacral local recurrence after rectal cancer treatment. Br 7 Surg 2010; 97: $1582-1587$.

14 Brown G, Radcliffe AG, Newcombe RG, Dallimore NS, Bourne MW, Williams GT. Preoperative assessment of prognostic factors in rectal cancer using high-resolution magnetic resonance imaging. Br 7 Surg 2003; 90: 355-364.

15 Bugg WG, Andreou AK, Biswas D, Toms AP, Williams SM. The prognostic significance of MRI-detected extramural venous invasion in rectal carcinoma. Clin Radiol 2014; 69: $619-623$.

16 Hunter CJ, Garant A, Vuong T, Artho G, Lisbona R, Tekkis $\mathrm{P}$ et al. Adverse features on rectal MRI identify a high-risk group that may benefit from more intensive preoperative staging and treatment. Ann Surg Oncol 2012; 19: 1199-1205.

17 Smith NJ, Barbachano Y, Norman AR, Swift RI, Abulafi AM, Brown G. Prognostic significance of magnetic resonance imaging-detected extramural vascular invasion in rectal cancer. Br 7 Surg 2008; 95: 229-236.

18 Siddiqui MRS, Simillis C, Hunter C, Chand M, Bhoday J, Garant A et al. A meta-analysis comparing the risk of metastases in patients with rectal cancer and MRI-detected extramural vascular invasion (mrEMVI) vs mrEMVInegative cases. Br $\mathcal{F}$ Cancer 2017; 116: 1513-1519.

19 Kusters M, Slater A, Betts M, Hompes R, Guy RJ, Jones OM et al. The treatment of all MRI-defined low rectal cancers in a single expert centre over a 5 -year period: is there room for improvement? Colorectal Dis 2016; 18: O397-O404.

20 Kusters M, Dresen RC, Martijn H, Nieuwenhuijzen GA, van de Velde CJ, van den Berg HA et al. Radicality of resection and survival after multimodality treatment is influenced by subsite of locally recurrent rectal cancer. Int $\mathcal{Z}$ Radiat Oncol Biol Phys 2009; 75: 1444-1449.

21 Ramlov A, Kroon PS, Jürgenliemk-Schulz IM, De Leeuw AA, Gormsen LC, Fokdal LU et al. Impact of radiation dose and standardized uptake value of (18)FDG PET on nodal control in locally advanced cervical cancer. Acta Oncol 2015; 54: $1567-1573$.
Have your say...

If you wish to comment on this, or any other article published in the BJS, you can:

Comment on the website www.bjs.co.uk

Follow \& Tweet on Twitter @BJSurgery 